\title{
Attitudes of Health Science Students towards Clients with Cancer
}

\author{
SHIMPACHIRO OGIWARA, RPT, SRP (UK), ONC (UK), MCPA (C), BPT (C), \\ MA (USA), PhD (USA) ${ }^{1)}$, YOKO IKEZAWA, RPT, BHSc ${ }^{2)}$ \\ 1) Department of Physical Therapy, School of Health Sciences, Faculty of Medicine, The \\ University of Kanazawa: 11-80 Kodatsuno 5, Kanazawa, Ishikawa 920-0942, Japan. \\ TEL +81 76-265-2616 FAX +81 76-234-4351 E-mail: oggy@mhs.mp.kanazawa-u.ac.jp \\ 2)Department of Medical Rehabilitation Services, Midorigaoka Hospital
}

\begin{abstract}
PURPOSE: To demonstrate attitudes of health science students towards clients with cancer (ATC). The objective was three-fold: 1) to describe health science students' ATC, 2) to compare ATC amongst health science students according to their professional discipline, academic seniority and gender, 3) to note whether their ATC differed according to: a) their experience with cancer clients during clinical placement; and/or b) their acquired perception through their class-work of the need for psychological support for cancer clients. RELEVANCE: To show how important a student's prior classroom instruction and positive experience in clinical placement is to the establishment of an empathic attitude to clients with cancer. PARTICIPANTS: A total of 860 students participated from five professional disciplines of the School of Health Sciences at the University of Kanazawa, Japan. Five hundred and sixty-eight responded appropriately with the rate of response being 66 per cent. METHOD: The ATC scale consisted of 30 statements with six responses $(+3,+2,+1,-1,-2,-3)$ for each statement. Two additional questions were provided on the questionnaire: a) whether or not a need for psychological support for such clients was perceived necessary as was instructed through their class-work; and b) students' experience with cancer clients during clinical placements. ANALYSIS: Descriptive analysis of student demographics, the Fisher's PLSD post-hoc test followed by multiple comparisons and the Mann-Whitney U test to determine any statistically significant difference in the ATC scores. RESULTS: Student nurses scored significantly high on the ATC scale, followed by laboratory science, physiotherapy, radiological technology and occupational therapy students. It was also found that all fourth year students scored significantly high on the ATC scale. The student nurses showed that they dealt with significantly large numbers of cancer clients during their clinical placements. The students who were affirmative to the two additional questions were found to have significantly higher ATC scores than those who were negative. CONCLUSION: Senior students' ATC was found to be more positive. Student nurses' approach to cancer clients was on a more person-to-person basis. Having experience alone with cancer clients was not sufficient to promote a positive ATC, but additional structured classroom instruction was found to play a necessary role in ATC.
\end{abstract}

Key words: Attitudes, Cancer, Health science students

(This article was submitted Jan. 5, 2004, and was accepted Jan. 27, 2004)

\section{INTRODUCTION}

Up to 30 years ago cancer used to be viewed as an incurable disease. However, recent advancements in cancer research and its management such as tumour dormancy therapy ${ }^{1)}$ and soft laser desorption $^{2)}$ have contributed towards accurate diagnosis and alleviation of its symptoms, leading 
to an increase in the survival rate of such clients. Although, since 1981, it remains the largest cause of death amongst the Japanese population, today, an increasing number of people live with cancer. Consequently, it is increasingly common for healthcare professionals to come into contact with such persons in the professional setting.

A fear of possible impending death of their clients with cancer by healthcare professionals may influence their attitudes towards such clients when making contact with them ${ }^{3)}$. These attitudes may, on occasion, be manifested negatively towards the client by the healthcare professional, consequently affecting his/her behaviour towards the client's management. There is, therefore, a need for studies that would reflect the influence of attitudes on reactions to persons with cancer in the context of increasing frequency of contact. The purpose of this study was to explore an appropriate approach that could be utilized by healthcare professionals when dealing with cancer clients. The objectives were: 1) to determine health science (HSc) students' attitudes towards cancer (ATC), 2) to compare ATC amongst HSc students, according to their academic seniority, professional discipline and gender, and 3 ) to note whether their ATC differed according to their various experiences with cancer clients during their clinical placement and/or their perception of the need for psychological support for such clients through their class-work. Examining the ATC of HSc students would provide a measuring stick by which to calculate their future needs for effective clinical practice. This information should be acquired during training, so as to raise a state of awareness that would be conducive to empathic treatment for management of the client with cancer in the clinical setting.

\section{METHODS}

\section{Instrumentation}

An Attitudes Towards Cancer Scale (ATC) in Likert format was used. The scale consists of 30 statements expressing both positive and negative sentiments about a person with cancer. In the construction of the scale two types of items were used; characteristic items and treatment items. Yuker and his associates developed an Attitudes Towards Disabled Persons (ATDP) Scale in 19664), and, in 1977, Tichenor and Rundall applied Form B of the ATDP to cancer clients by a careful re- wording of the statements, resulting in the creation of the ATC Scale (see Appendix) ${ }^{5}$. For example, item 8 was modified from Most people feel uncomfortable when they associate with disabled people, to Most people feel uncomfortable when they associate with people who have cancer. ATC scores may be interpreted as reflecting either the respondent's perception of a cancer client as basically the same as or different from a non-cancer client. The perception of differences in the characteristics of cancer clients and their treatment may be interpreted as rejection or prejudice of such clients.

In addition to the ATC scale, two additional questions were incorporated into this study concerning a) students' experience with cancer clients during clinical placements and $b$ ) whether or not a need for psychological support for such clients was perceived necessary as was instructed through their class-work.

\section{Scoring}

Six responses were provided for each of the ATC statements, and the items were scored in such a way that a score of 3 indicated strong agreement and that of -3 indicated strong disagreement with the statement. There was no neutral or zero point provided on the scale, so the respondent had to indicate to some extent either agreement or disagreement with each item.

Eleven of the 30 statements were worded positively, whereas the remaining 19 items were worded negatively, which was an attempt to adjust for any tendency on the part of the respondents to consistently make positive or negative responses regardless of the content of the statements. The signs of the responses to statements with negative wording were first reversed. For example, statement 2, People with cancer should not have to pay income taxes, was considered a negatively worded statement because it suggested that people with cancer were different from people without cancer. Accordingly, a response of -2 would be reversed to 2 . Reversals of signs such as this were made for items 2, 5, 8, 9, 11, 14-21, 23, 24, 25, 27, 29 , and 30 . Once the signs of the responses to negatively worded items were reversed from negative to positive or vice versa, the individual scores for each item were then totalled.

The lowest possible score attainable was -90 and the highest 90 . A constant of +90 was added to 
eliminate negative values. Thus, the final ATC score ranged from 0 to 180 . A high score indicated that the cancer client was viewed in a like manner to the non-cancer client, while a low score indicated a perception of dissimilarity between the two clients.

\section{Participants and procedures}

The original English version of the statements was translated into Japanese by the authors. This was then critically examined by therapists in the University of Kanazawa Hospital Departments of Physical Therapy and Occupational Therapy.

Participants in our survey were undergraduate HSc students, and were a sample of convenience. Within the total number of these 860 participants 587 responded. Out of these, there were 206 students from the Department of Nursing, 124 from the Department of Radiological Technology, 125 from the Department of Laboratory Science, 67 from the Department of Physical Therapy and 65 from the Department of Occupational Therapy. Transfer students* were excluded from the study because their professional experience might have affected the results (*Transfer students are those who are already qualified in their respective professions and are undergoing a further course of study leading to the Degree of Bachelor of Health Science).

Within the population designated in this study four hypotheses were presented. Hypothesis one: The higher the year of academic seniority of the students, the higher their ATC score would be. Hypothesis two: There would be no difference in the ATC score of the respondents amongst the professional disciplines. Hypothesis three: There would be no difference in the ATC score between men and women students. Hypothesis four: The ATC score would be high amongst students who had experienced cancer clients during their clinical placements and had perceived of the need for psychological support for such clients from prior class-work.

The survey was conducted in a classroom situation during December 2002. Out of 587 responses, 19 incomplete questionnaires were excluded from the analysis. Thus, the final rate of response was 66 per cent.

\section{Statistics}

The demographic data of the respondents were first compiled followed by the calculation of the mean, standard deviation, range and confidence interval for the dependent variables. The mean ATC scores were analysed for each professional discipline and academic seniority using the Fisher's PLSD post-hoc test, followed by multiple comparisons. Similarly, the mean ATC scores between the genders were analysed using the MannWhitney $U$ test. The statistical difference was also tested using the Mann-Whitney $U$ test to examine the mean ATC scores concerning the two additional questions provided. Probability values of $<0.05$ were considered statistically significant, and computer softwares Microsoft Excel 2001 and StatView 5 were used for the data analysis.

\section{RESULTS}

The demographic data of the respondents are shown in the Table 1, together with the ATC scores and the rate of response for all of the students to the two additional questions described in Methods.

The mean ATC scores of all the fourth year students were significantly higher than those of the first, second, and third year students with hypothesis one being accepted. Although the ATC score of the third year students did not differ from those of the first and fourth year students, it was significantly lower than that of the second year students.

Out of all the first year students the student nurses scored significantly higher on the ATC scale than the student laboratory technologists and student occupational therapists. Furthermore, out of all the third year students the student nurses scored significantly higher on the ATC scale than those from radiological technology and physiotherapy. Similarly, the student laboratory technologists scored significantly higher on the ATC scale than the student radiological technologists and student physiotherapists.

The mean ATC scores for the student nurses were the highest followed by the laboratory science, physiotherapy, radiological technology and occupational therapy students. Fisher's PLSD post hoc test also revealed that the student nurses scored significantly higher on the ATC scale than the radiological technology and occupational therapy students. Thus, hypothesis two was rejected. Of the student nurses, however, the fourth year students scored significantly higher on the ATC scale than the second year students. Of the student radiological technologists both the second and 
Table 1. Demographic characteristics and ATC scores of respondents concerning their experience in dealing with cancer clients and their perception of the need for psychological support for cancer clients

\begin{tabular}{|c|c|c|c|c|c|c|c|c|c|c|c|c|}
\hline \multirow{2}{*}{$\begin{array}{l}\text { Professional } \\
\text { discipline }\end{array}$} & \multirow{2}{*}{ AS } & \multicolumn{3}{|c|}{ Respondents } & \multirow{2}{*}{$\begin{array}{c}\text { Age } \\
\text { Mean (SD) }\end{array}$} & \multicolumn{3}{|c|}{ ATC scores } & \multirow{2}{*}{$\begin{array}{r}\mathrm{aY} \\
\%\end{array}$} & \multirow{2}{*}{$\begin{array}{c}\mathrm{aN} \\
\%\end{array}$} & \multirow{2}{*}{$\begin{array}{c}\mathrm{bY} \\
\%\end{array}$} & \multirow{2}{*}{$\begin{array}{c}\mathrm{bN} \\
\%\end{array}$} \\
\hline & & $\mathrm{M}$ & W & $\mathrm{n}$ & & Mean (SD) & Range & $\mathrm{CI}$ & & & & \\
\hline \multirow[t]{4}{*}{ Nursing } & $1 \mathrm{st}$ & 3 & 47 & 50 & $19.0(0.1)$ & $97.38(1.73)$ & $75-121$ & $93.91-100.85$ & 100 & 0 & 10 & 90 \\
\hline & 2nd & 2 & 57 & 59 & $19.9(0.1)$ & $92.31(1.58)$ & $69-112$ & $89.14-95.47$ & 58 & 42 & 10 & 90 \\
\hline & $3 \mathrm{rd}$ & 1 & 40 & 41 & $21.2(0.1)$ & $97.63(1.65)$ & $76-118$ & $94.30-100.97$ & 76 & 24 & 95 & 5 \\
\hline & 4 th & 0 & 56 & 56 & $21.9(0.1)$ & $101.79(1.45)$ & $79-123$ & 98.89-104.68 & 91 & 9 & 100 & 0 \\
\hline \multirow{4}{*}{$\begin{array}{c}\text { Radiological } \\
\text { technology }\end{array}$} & $1 \mathrm{st}$ & 24 & 12 & 36 & $19.1(0.1)$ & $90.14(1.67)$ & $62-114$ & $86.75-93.53$ & 0 & 94 & 6 & 94 \\
\hline & 2nd & 16 & 13 & 29 & $20.0(0.1)$ & $96.10(2.71)$ & $53-129$ & $90.55-101.66$ & 0 & 100 & 0 & 100 \\
\hline & $3 \mathrm{rd}$ & 17 & 18 & 35 & $21.5(0.3)$ & $91.49(2.50)$ & $57-122$ & $86.40-96.57$ & 11 & 89 & 11 & 89 \\
\hline & 4 th & 15 & 9 & 24 & $22.3(0.2)$ & $97.75(2.88)$ & $68-131$ & 91.79-103.71 & 67 & 33 & 4 & 96 \\
\hline \multirow{4}{*}{$\begin{array}{l}\text { Laboratory } \\
\text { science }\end{array}$} & $1 \mathrm{st}$ & 6 & 26 & 32 & $19.4(0.2)$ & $92.09(2.36)$ & 69-134 & $87.28-96.91$ & 9 & 91 & 6 & 94 \\
\hline & 2nd & 3 & 27 & 30 & $20.2(0.2)$ & $94.53(1.64)$ & $75-116$ & $91.17-97.90$ & 3 & 97 & 3 & 97 \\
\hline & $3 \mathrm{rd}$ & 4 & 24 & 28 & $20.9(0.1)$ & $98.21(2.93)$ & $65-128$ & $92.21-104.22$ & 0 & 100 & 7 & 93 \\
\hline & 4 th & 6 & 29 & 35 & $22.1(0.1)$ & $98.11(1.67)$ & $76-115$ & $94.73-101.50$ & 17 & 83 & 3 & 97 \\
\hline \multirow{4}{*}{$\begin{array}{l}\text { Physical } \\
\text { therapy }\end{array}$} & $1 \mathrm{st}$ & 7 & 9 & 16 & $19.1(0.2)$ & $93.06(4.26)$ & $52-114$ & $83.97-102.15$ & 0 & 100 & 13 & 88 \\
\hline & 2nd & 7 & 8 & 15 & $20.5(0.1)$ & $94.33(3.34)$ & $75-112$ & $87.16-101.51$ & 7 & 93 & 7 & 93 \\
\hline & $3 \mathrm{rd}$ & 14 & 6 & 20 & $22.5(0.9)$ & $90.05(2.35)$ & $70-110$ & $85.14-94.96$ & 20 & 80 & 20 & 80 \\
\hline & 4 th & 5 & 11 & 16 & $22.7(0.6)$ & $98.94(2.60)$ & $78-115$ & $93.40-104.47$ & 56 & 44 & 6 & 94 \\
\hline \multirow{5}{*}{$\begin{array}{l}\text { Occupational } \\
\text { therapy }\end{array}$} & $1 \mathrm{st}$ & 2 & 13 & 15 & $19.0(0.2)$ & $89.40(2.61)$ & $70-104$ & $83.79-95.01$ & 0 & 100 & 7 & 93 \\
\hline & 2 nd & 3 & 15 & 18 & $20.3(0.2)$ & $94.78(1.85)$ & 79-104 & $90.87-98.68$ & 6 & 94 & 6 & 94 \\
\hline & $3 \mathrm{rd}$ & 1 & 15 & 16 & $21.3(0.2)$ & $92.00(2.52)$ & $76-111$ & $86.62-97.38$ & 0 & 100 & 13 & 88 \\
\hline & 4 th & 1 & 15 & 16 & $22.4(0.3)$ & $97.94(2.65)$ & 69-115 & $92.28-103.59$ & 6 & 94 & 6 & 94 \\
\hline & Total & 137 & 450 & 587 & $20.7(0.2)$ & $94.90(2.35)$ & $52-134$ & $90.02-99.79$ & 36 & 64 & 22 & 78 \\
\hline
\end{tabular}

aY: Number of respondents who had experience of cancer clients during their clinical placements; aN: Number of respondents who had no experience of cancer clients during their clinical placements; bY: Number of respondents who had perceived the need for psychological support for cancer clients through their class-work; bN: Number of respondents who had not perceived the need for psychological support for cancer clients through their class-work AS: Academic seniority; M: Men students; W: Women students; $\mathrm{n}$ : Number of respondents; SD: Standard deviation; CI: confidence interval.

fourth year students scored significantly higher on the ATC scale than the first year students. Of the student laboratory technologists the fourth year students scored significantly higher on the ATC scale than the first year students. Of the student physiotherapists the fourth year students scored significantly higher on the ATC score than the third year students. Of the student occupational therapists the fourth year students scored significantly higher on the ATC scale than the first year students.

The women students, in general, scored higher on the ATC scale than the men students, but there was no significant difference between them. Thus, hypothesis three was accepted.

As for the response to the additional Question a, the percentage of respondents who were affirmative was significantly higher for the student nurses than for those from the other professional disciplines.
However, as a whole, there was no significant difference in the ATC score between the students who were affirmative and those who were negative to Question a. On the contrary, there was a significant difference in the ATC scores between the students who responded affirmative to Question $\mathrm{b}$ and those who did not $(p<0.05)$. In addition, the ATC scores of the students who were affirmative to both questions were significantly high $(p<0.01)$. Thus, hypothesis four was accepted.

\section{DISCUSSION}

\section{Comparison amongst academic seniority}

All the fourth year students seem to perceive cancer clients as basically the same as non-cancer clients when compared to those from other academic years, the reason being that most of the professional subjects of the senior year and their 
clinical placements are completed by the end of the first term of the fourth year. Thus, students in the fourth year already have a deeper understanding of clients with cancer and its implication, both physically and psychologically, and have also acquired appropriate skills to interact with such clients. In other words, the fourth year students are tentatively ready to practice their respective professions.

The reason for the low ATC score of the third year students is not clear, although students from third year nursing and laboratory technology had higher scores on the ATC scale than the second year students from all the other disciplines. Generally, the third year students from radiological technology, physiotherapy and occupational therapy scored lower on the ATC scale than the second year students from the same disciplines, lowering the mean ATC score of the third year students as a whole. The third year students may tend to be more cynical than the first and second year students, but should be awakened from this when they visit the real world in the fourth year. Nevertheless, in general, the ATC scores rose with students' seniority.

\section{Comparison amongst professional disciplines}

The ATC score of the nursing students was significantly higher than those of the radiological technology and occupational therapy students. The reason for the high ATC score of the student nurses may be that the field of nursing is more directly involved in the management of clients with cancer than professionals from other healthcare disciplines. The fact that many opportunities arise for student nurses to have contact with clients with cancer is evidenced by their large number of positive responses to questions concerning experience with cancer clients during their clinical placements. In addition, student nurses' perception of the need for psychological support learnt through class-work was high compared to that of students from the other professional disciplines.

People with a negative attitude towards physically challenged persons can be considered as unsuited to an occupation that involves such a person $^{6)}$. A characteristic common to clients with a physical disability or with cancer is mental anguish, so, therefore, the above statement could be paraphrased as People with negative attitudes towards individuals with cancer are not suited to occupations that involve such persons.

In the field of physiotherapy, in addition to the application of mobilising and oedema reduction techniques for post-mastectomy ${ }^{7}$ and cardiopulmonary treatment for the client with postoperative lung cancer, modalities such as massage, thermotherapy and hydrotherapy are largely administered as palliative care in a hospice setting for clients with terminal cancer ${ }^{8)}$. Because physiotherapy (and also occupational therapy to a large extent) deals mainly with clients who have biomechanical problems related to neuro-musculoskeletal conditions, but not directly with the cancer itself, the students of these two healthcare professions may have shown less interest in ATC than the student nurses did.

\section{Comparison between genders}

This study shows that both men and women students from all the disciplines appear to have a similar ATC. Also, no gender difference was apparent in a survey conducted concerning attitudes towards physically challenged persons of hands-on healthcare professionals including doctors and nurses, and technical healthcare professionals such as pharmacists, radiographers and laboratory technologists, in addition to non-healthcare workers such as medical secretaries ${ }^{9)}$. The result of our present investigation can be seen to be in agreement with the above survey if we consider cancer clients and physically challenged persons in the same context and look at the attitudes of healthcare professionals towards the healthcare consumer. However, women's attitudes towards physically challenged persons (ATPCP) have been shown to be more positive than those of men in an investigation that was carried out amongst health science students ${ }^{10)}$. In addition, it is known that women consistently score higher on the ATPCP scale than men $^{5)}$. In our present investigation the women students tended to have a more positive ATC, though there was no statistically significant difference in the ATC score between the women and men students.

\section{Effect of clinical placements}

Healthcare professionals, in addition to such students as ours in the survey, have been shown to possess positive attitudes towards such persons after having received education on, and had experience with, physically challenged persons ${ }^{10-14)}$. In other 
words, it has been shown that experience alone or classroom instruction alone is insufficient to modify one's attitude towards clients with physical disability, but both are deemed necessary. The results of this study show agreement with the above statement.

Possible reasons why experience alone with cancer clients during clinical placement may not necessarily contribute to a students' positive ATC are 1) authoritarian attitude of student towards the client resulting in an unequal relationship, 2) lack of maturity manifested by insufficient empathy with the client, 3) comparatively short duration of clinical placement resulting in insufficient experience $^{8)}$ and 4) unrealistic concept of the client by the student.

Those respondents who have already learned of the need for psychological support of the cancer client through classroom instruction were found to show a positive ATC. However, no information was available on the various elective subjects taken by the respondents and of their influence on, and contribution to, a positive or negative ATC of the students. It is known that student nurses in the School of Health Sciences at the University of Kanazawa take one professional subject entitled Management of Clients with Chronic and Terminal Conditions in their course of study, and its contents are concerned with ATC. So, through this educational channel, a positive ATC may have been inculcated in the student nurses. As previously mentioned, the experience from a student's clinical placement may be a contributing factor that influences their future positive or negative ATC depending on the individual's perception of the experience.

\section{CONCLUSION}

Based on the results of the cross-sectional survey, using a 30-item Likert-type questionnaire, the ATC of the health science students at the University of Kanazawa were found to be generally positive. It was also found that having experience alone with cancer clients is not sufficient to promote a positive A TC, but additional structured classroom instruction is required to instil such an attitude, and this preferably must be taught prior to clinical placement.

\section{REFERENCES}

1) Tumour dormancy therapy. Hokukoku Newspaper, 17 Nov. 2002, 32 (in Japanese).

2) Japan International Cooperation Agency: Nobel-prizeclass technology for developing countries. Frontier, 2002, 40: 21 (in Japanese).

3) Ikemi Y: Total healthcare and terminal care. In: Ikemi Y, Nagata K (eds.), Terminal Care in Japan: Practice of Terminal Care Medicine. Tokyo: Seishin Co., 1984, pp 3-21 (in Japanese).

4) Yuker HE, Block JR, Younng JH: The measurement of attitudes toward disabled persons. In: Human Resources Study No. 7. New York: Human Resource Center, 1966.

5) Tichenor CC, Rundall TG: Attitudes of physical therapists toward cancer. Phys Ther, 1977, 57: 160165.

6) Biordi B, Oermann MH: The effect of prior experience in a rehabilitation setting on students' attitudes toward the disabled. Rehabil Nurs, 1993, 18: 95-98.

7) Molinaro J, Kleinfeld M, Lebed S: Physical therapy and dance in the surgical management of breast cancer. Phys Ther, 1986, 66: 967-969.

8) Mackey KM, Sparling JW: Experiences of older women with cancer receiving hospice care: significance for physical therapy: a clinical report. Phys Ther, 2000, 80: 459-468.

9) Hakuno A, Takatsuka H, Hirai N: Study on attitudes toward people with disabilities: pilot study by IDP. Sogo Rihabiriteshon, 1999, 565-573 (in Japanese).

10) Felton GS: Changes in attitudes toward disabled persons among allied health paraprofessional trainees in an interdisciplinary setting. Percep Motor Skills, 1975, 40: 118.

11) Mitchell KR, Hays M, Gordon J, et al.: An investigation of the attitudes of medical students to physically disabled people. J Med Ed, 1984, 18: 2123.

12) Örmann MH, Lindgren CL: An educational program's effects on students' attitudes toward people with disabilities: a 1-year follow-up. Rehabil Nurs, 1995, 20: 6-10.

13) Paris MJ: Attitudes of medical students and health-care professionals toward people with disabilities. Arch Phys Med Rehabil, 1993, 74: 818-825.

14) Ogiwara S: Attitudes toward disabled persons (ATDP): health science students' ATDP and their modification strategy. PTJ, 2000, 34: 61-66 (in Japanese). 


\section{Appendix: STATEMENTS ON ATTITUDE TOWARDS CANCER ${ }^{5)}$}

1. Persons with cancer are usually friendly.

2. People with cancer should not have to pay income taxes.

3. People with cancer are no more emotional than other people.

4. Persons with cancer can have a normal social life.

5. Most persons with cancer have a chip on their shoulder.

6. Workers with cancer can be as successful as other workers.

7. Very few persons with cancer are ashamed of their illness.

8. Most people feel uncomfortable when they associate with people who have cancer.

9. People with cancer show less enthusiasm than other people.

10. People with cancer do not become upset any more easily than other people.

11. People with cancer are often less aggressive than normal people.

12. Most persons with cancer get married and have children.

13. Most persons with cancer do not worry any more than anyone else.

14. Employers should not be allowed to fire employees with cancer.

15. People with cancer are not as happy as other people.

16. People with advanced cancer are harder to get along with than are those with minor illnesses.

17. Most people with cancer expect special treatment.

18. Persons with cancer should not expect to lead normal lives.

19. Most people with cancer tend to get discouraged easily.

20. The worst thing that could happen to a person would be for him to get cancer.

21. Children with cancer should not have to compete with other children.

22. Most people with cancer do not feel sorry for themselves.

23. Most people with cancer prefer to work with other people who have cancer.

24. Most persons with advanced cancer are not as ambitious as other people.

25. Persons with cancer are not as self-confident as physically normal persons.

26. Most persons with cancer do not want more affection and praise than other people.

27. It would be best if a person with cancer married another person who has cancer.

28. Most people with cancer do not need special attention.

29. Persons with cancer want more sympathy than other people.

30. Most persons with cancer have different personalities than normal persons. 